\title{
Adenylate kinase 2 (AK2) promotes cell proliferation in insect development
}

\author{
Ru-Ping Chen ${ }^{1}$, Chun-Yan Liu', Hong-Lian Shao ${ }^{1}$, Wei-Wei Zheng ${ }^{1,2}$, Jin-Xing Wang ${ }^{1}$ and Xiao-Fan Zhao ${ }^{1 *}$
}

\begin{abstract}
Background: Adenylate kinase 2 (AK2) is a phosphotransferase that catalyzes the reversible reaction 2ADP(GDP) ATP(GTP) + AMP and influences cellular energy homeostasis. However, the role of AK2 in regulating cell proliferation remains unclear because AK2 has been reported to be involved in either cell proliferation or cell apoptosis in different cell types of various organisms.

Results: This study reports AK2 promotion of cell proliferation using the lepidopteran insect Helicoverpa armigera and its epidermal cell line HaEpi as models. Western blot analysis indicates that AK2 constitutively expresses in various tissues during larval development. Immunocytochemistry analysis indicates that AK2 localizes in the mitochondria. The recombinant expressed AK2 in E. coli promotes cell growth and viability of HaEpi cell line by 3-(4, 5-Dimethylthiazol-2-yl)-2, 5-diphenyltetrazolium bromide (MTT) assay. AK2 knockdown in larvae by RNA interference causes larval growth defects, including body weight decrease and development delay. AK2 knockdown in larvae also decreases the number of circulating haemocytes. The mechanism for such effects might be the suppression of gene transcription involved in insect development caused by AK2 knockdown.
\end{abstract}

Conclusion: These results show that AK2 regulates cell growth, viability, and proliferation in insect growth and development.

Keywords: Helicoverpa armigera, Adenylate kinase 2 (AK2), Cell growth and viability, RNA interference

\section{Background}

Various cellular functions need ATP for energy supply. Adenylate kinase (AK or ADK) is a phosphotransferase that catalyzes the reversible reaction $2 \mathrm{ADP}(\mathrm{GDP}) \leftrightarrow$ $\mathrm{ATP}(\mathrm{GTP})+\mathrm{AMP}$ in the presence of $\mathrm{Mg}^{2+}$ and influences cellular energy homeostasis and cellular adenine nucleotide metabolism [1,2]. The widespread and highly conserved distribution of AK has been reported in organisms from prokaryotes to eukaryotes. Prokaryotic cells [3] and eukaryotic yeasts [4] have a single-type gene of AK essential for their survival, which indicates the significance of AK in energy metabolism. Multicellular organisms have obtained diverse isoenzymes of AK through evolution. To date, eight isoenzymes of the AK family comprising AK1-AK8 have been identified in

\footnotetext{
* Correspondence: xfzhao@sdu.edu.cn

${ }^{1}$ The Key Laboratory of Plant Cell Engineering and Germplasm Innovation, Ministry of Education; Shandong Provincial Key Laboratory of Animal Cells and Developmental Biology, School of Life Sciences, Shandong University, Shandong, Jinan 250100, China

Full list of author information is available at the end of the article
}

vertebrates forming a circuit in monitoring cell energy metabolism and AMP signal transduction [5]. Among these isoenzymes, AK2 is uniquely located in the mitochondrial intermembrane space distributed in the liver and kidney [6]. The unique subcellular localization suggests that AK2 plays a unique role in energy metabolism and energy transfer by regulating the ATP/ADP rate between the cytoplasma matrix and the mitochondria [7].

Several studies have been conducted on the functions of AK. AK1 knockout in mice shows compromised energy deficiency in the heart and skeletal muscles under metabolic stress [8]. The growth and development of Caenorhabditis elegans is suppressed after the knockdown of AK6 [9]. The knockdown of zebra fish AK2, the only type of AK in leukocytes, causes leukocyte development defects, thus indicating the importance of AK2 in leukocyte differentiation [10]. A recent study reveals that the homozygous $A K 2$ $(-/-)$ larvae of Drosophila melanogaster ceases growth and causes death before reaching the third instar larval stage, indicating that AK2 is necessary for the growth and development of D. melanogaster [11].

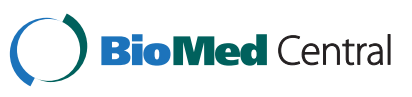


AK2 has been reported to be involved in cell proliferation. In humans, mutations in the AK2 gene cause a profound haematopoietic defect because AK2 is required for the proliferation and differentiation of haematopoetic cells [12]. However, others report the involvement of AK2 in cell apoptosis as AK2 translocates from the mitochondrial intermembrane space into the cytosol together with cytochrome $c$ during apoptosis [13]. AK2 participates in mitochondrial apoptosis by forming a complex with Fasassociating protein with death domain (FADD) and caspase 10 in the HeLa cell line, whereas AK2 knockdown attenuates apoptosis [14]. Therefore, the real function of AK2 in regulating cell growth or apoptosis remains unclear.

This study used a lepidopteran insect $H$. armigera and its epidermal cell line (HaEpi) [15] as models to investigate the roles of AK2 in cell growth and development. The results show that AK2 from $H$. armigera shares high identity with other $\mathrm{AK} 2$ from various animals. AK2 is constitutively expressed in various tissues during larval development and locates in the mitochondria, similar to AK2 in vertebrates. Recombinantly expressed AK2 in Escherichia coli increases HaEpi cell growth and viability. AK2 knockdown in larvae results in larval growth arrest, body weight decrease, developmental stage delay, and decrease of circulating haemocytes. The mechanism behind these phenomena is the suppression of gene transcription involved in insect development caused by AK2 knockdown. Results show that AK2 plays critical roles in cell proliferation and insect development.

\section{Results}

Helicoverpa AK2 shares high identity with AK2 in various animals

The cDNA of $H$. armigera AK2 is 1,013 bp in length and encodes a 242 amino acid residue protein with a molecular weight of $27 \mathrm{kDa}$. The predicted isoelectric point of
Helicoverpa AK2 is 8.9. No signal sequence is detected. AK2 contains a core ADK domain flanked by an ATP binding domain LID. Helicoverpa AK2 shares higher identities with other AK2 genes from D. melanogaster (73\%), Anopheles gambiae (72\%), Danio rerio (74\%), Mus musculus (73\%), and Homo sapiens (72\%). Phylogenetic analysis shows that AK2 from various animals cluster into two main groups: 1) AK2 from vertebrates and 2) AK2 from insects. Helicoverpa AK2 is clustered with insect AK2 (Additional file 1 Figure S1).

\section{AK2 is constitutively expressed in various tissues during larval development}

The expression profiles of AK2 were examined in the tissues during larval development to investigate the role of $\mathrm{AK} 2$ in insect development. Western blot shows that AK2 expresses in various tissues, including in the epidermis, midgut, body fat, and haemocytes. The translation levels of AK2 reflect a constitutive expression in four tissues during development from the 5 th instar $24 \mathrm{~h}$ larvae (5-24) to the 1 st day pupae ( $\mathrm{p} 0$ ). These results imply that AK2 is essential during insect larval development (Figure 1).

\section{AK2 is co-localized with mitochondria}

Immunocytochemistry was performed in the Helicoverpa epidermal cell line (HaEpi) to determine the location of AK2 in the cells. Results show that AK2 locates in the cytoplasm and appears as dots (Figure 2a), implying its location in the cellular organs. Further co-localization of AK2 with mitochondria (Figure 2b) shows that AK2 is mostly overlapped with mitochondria. An orange color results from the overlap of green-colored AK2 and redcolored mitochondria (Figure 2d). Some dots of AK2 do not overlap completely with mitochondria, owing to the difference in the focus of the images from the microscope.

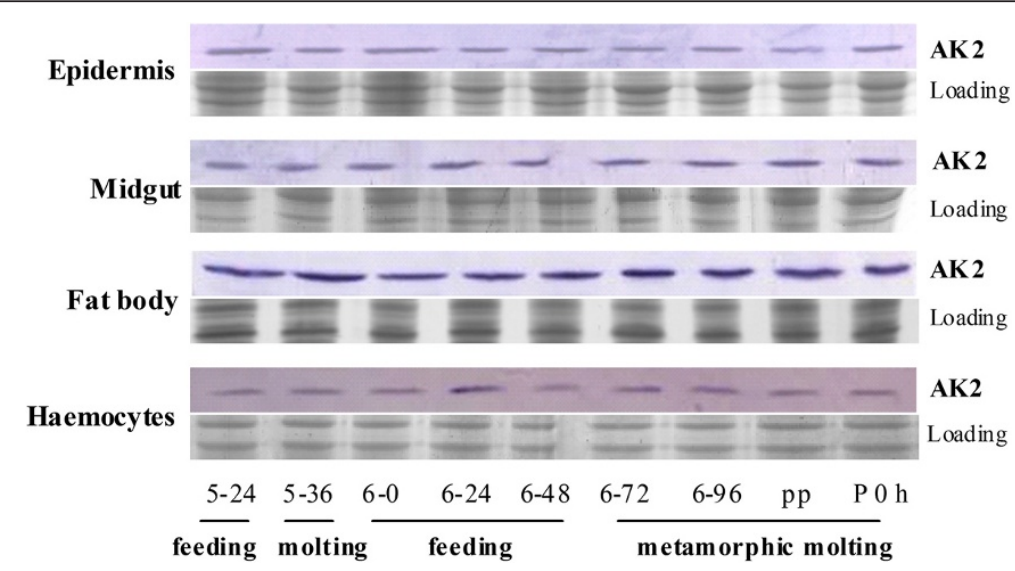

Figure 1 Western blot analysis of AK2 expression profiles in tissues at different developmental stages. 5-24 and 5-36 are the hours of 5th instar larvae after ecdysis; 6-0, 6-24, 6-48, 6-72, and 6-96 are the hours of 6th instar larvae after ecdysis; pp indicates prepupae (6th instar 120-140 h larvae); and p 0 indicates new pupae. The loading control is SDS-PAGE showing the loaded protein quantity and quality (12.5\% gel). 

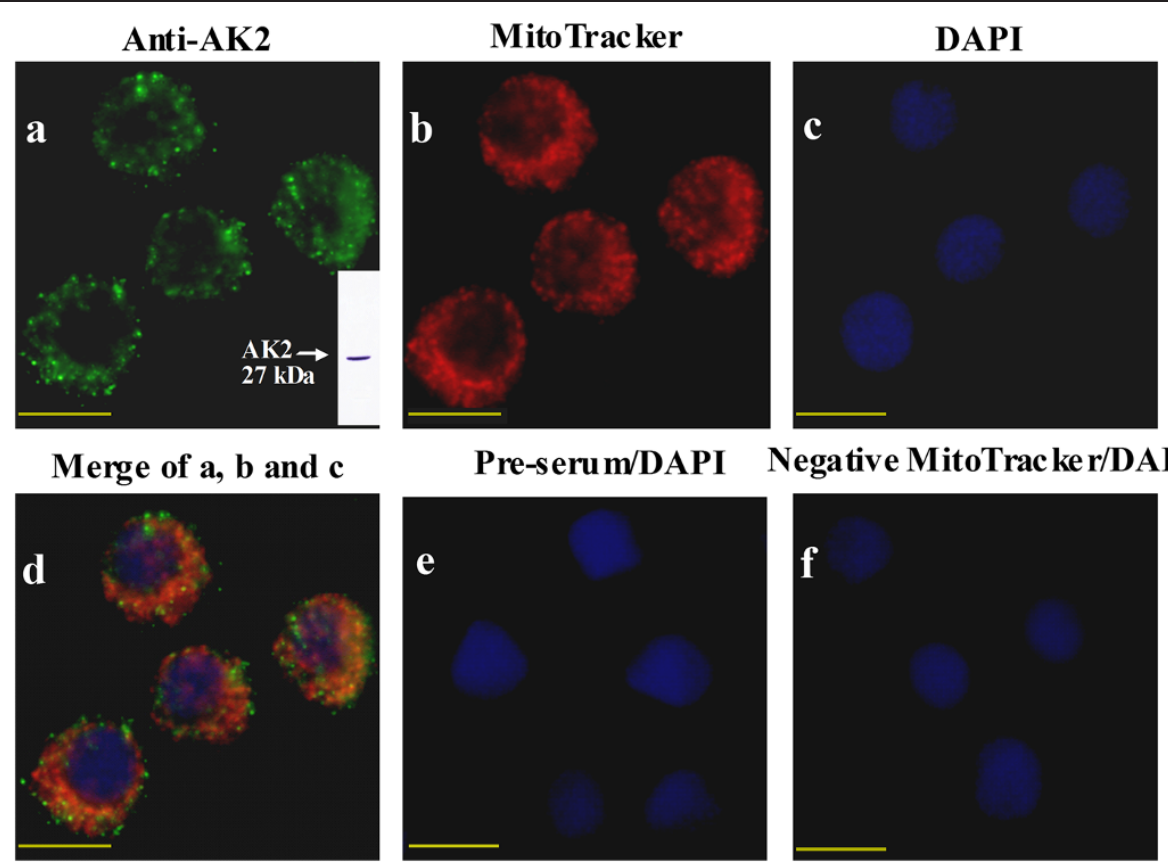

\section{Pre-serum/DAPI Negative MitoTracker/DAPI}
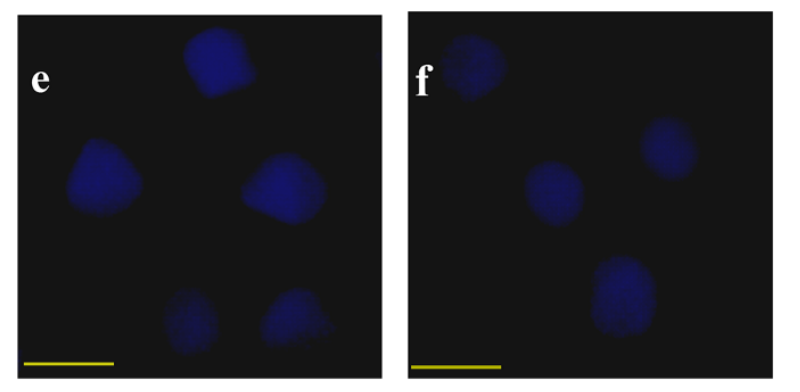

Figure 2 Immunohistochemistry showing the co-localization of AK2 with mitochondria. a. Detection of AK2 in the cells with the rabbit polyclonal antiserum against Helicoverpa AK2 and the goat anti-rabbit-Alexa Fluor 488, the green fluorescence indicates AK2, the column in panel $a$ is the Western blot showing the specificity of the antibody against Helicoverpa AK2 using fat body from the 5th instar feeding larvae as the protein sample. b. Detection of mitochondria with MitoTracker, red fluorescence indicates mitochondria. c. DAPI-stained nucleus, blue fluorescence indicates the nucleus. d. Merging of images in a, b, and c, the orange color is caused by the overlap of green-colored AK2 and redcolored mitochondria. e. Preserum as a negative control for the antiserum against AK2. f. The negative control without MitoTracker. Bar is $20 \mu m$.

The preserum control did not produce any green fluorescence, indicating that the antiserum against AK2 is specific to AK2 (Figure 2e). The non MitoTracker control indicates the specificity of mitochondria staining (Figure 2f). This result suggests that AK2 locates in the mitochondria.

\section{Recombinantly expressed AK2 in E. coli promotes cell growth and viability}

AK2 was expressed as a soluble His-tagged protein in $E$. coli and purified to homogeny to analyze the function of AK2 in cell growth. The molecular mass of the purified His-AK2 is about $33 \mathrm{kDa}$, comprising AK2 $(27 \mathrm{kDa})$ and His-tag $(6 \mathrm{kDa})$ (Figure 3A).

The purified His-AK2 was added into the Grace's medium to culture epidermal cells (HaEpi) to assay the function of AK2. The results of MTT assay show that His-AK2 promotes cell growth and viability at concentrations from $0.313 \mu \mathrm{M}$ to $20 \mu \mathrm{M}$ in $72 \mathrm{~h}$, compared with the His-VP28 negative control, an envelope protein of the white spot syndrome virus expressed in E. coli fused with His-tag (Figure 3B).

Western blot analysis shows that His-AK2 entered the HaEpi cells to promote cell growth and viability, because His-AK2 was only detected from cells incubated with His-AK2. It was present in neither the PBS buffer used in washing the His-AK2-incubated cells nor in the non-
His-AK2-incubated cells (Figure 3C). To confirm the entrance of the recombinant expressed His-AK2 in the cells, immunocytochemistry was done and His-AK2 was detected in the cells by the antibody against His-tag (Figure 3D).

\section{AK2 knockdown represses larval growth and development}

$A K 2$ was knocked down by RNAi via continuously feeding the newly hitched larvae with $E$. coli that expresses dsRNA of $A K 2$ until the larvae stopped eating (6th instar $72 \mathrm{~h}$ ) to investigate the roles of AK2 in vivo in insect development. Western blot results show that AK2 was knocked down systemically in various tissues, including epidermis, midgut, body fat, and haemocytes by feeding dsAK2-expressing E. coli (Figure 4A).

Due to AK2 knockdown, the larvae that fed on dsAK2-expressing E. coli exhibited growth defects and development delay, by comparison with the control that fed on $d s G F P$-expressing $E$. coli. The larvae grew slowly after knockdown of $A K 2$ and the body weight was lower than those of the controls (Figure 4B). In addition, the pupation time in the larvae that fed on $d s A K 2$ delayed about 3 days compared the control (Figure 4C). These results suggest that AK2 is necessary for larval growth and development. 

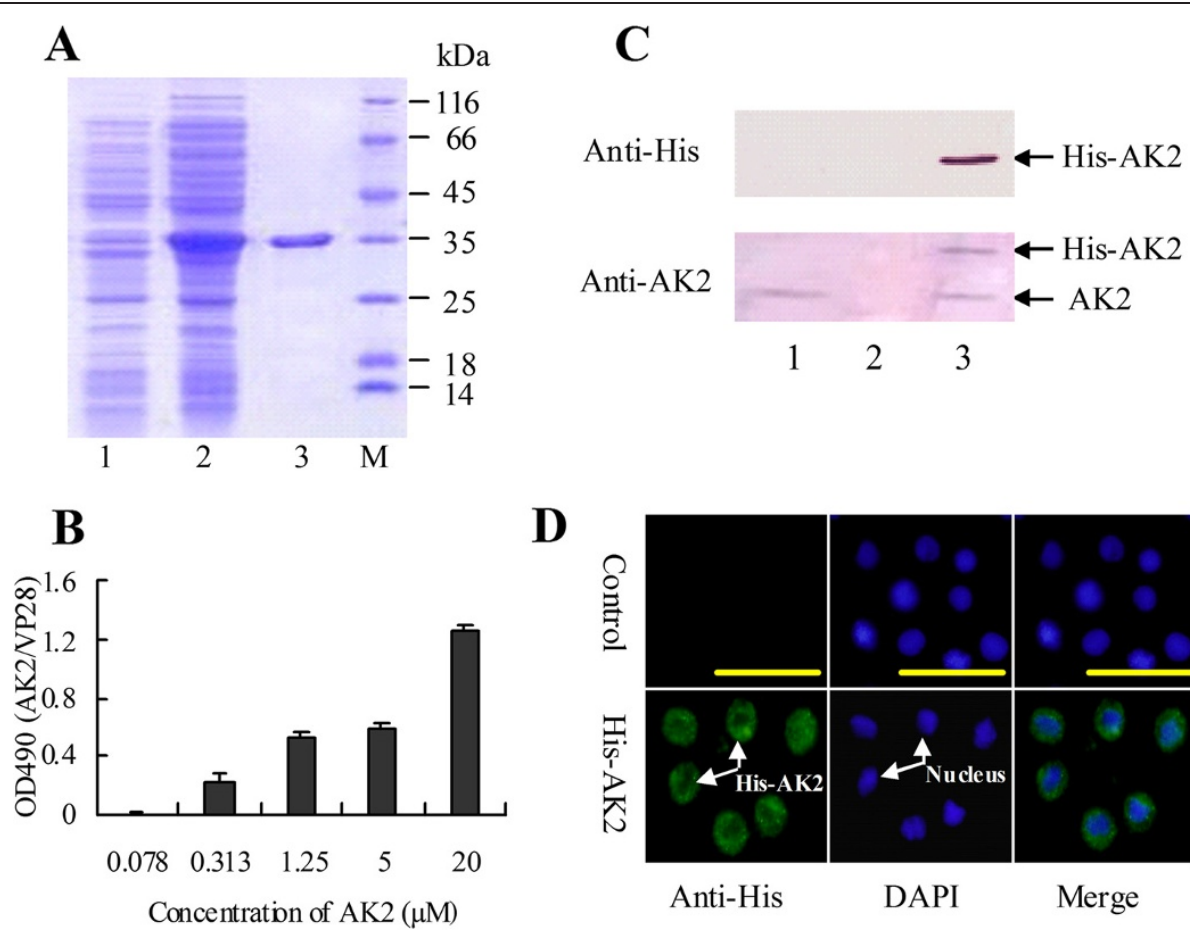

D

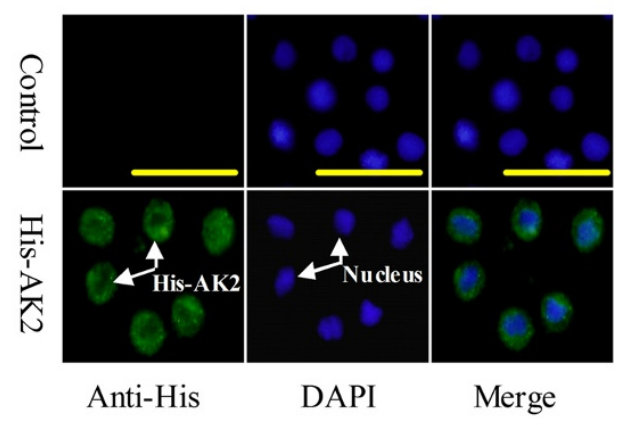

Figure 3 The function of AK2 in promoting cell growth and viability. A. SDS-PAGE (12.5\% gel) showing the recombinant expression and purification of His-AK2 in E. coli. Lane 1, total proteins of E. coli without induction; lane 2, total proteins after induction by IPTG; lane 3, purified His-AK2; M, protein marker. B. MTT assay to examine the role of AK2 in cell growth and viability. Halicoverpa epidermal cells (HaEpi) were incubated in Grace's medium containing different concentrations of His-AK2 $(0.078,0.313,1.25,5$, and $20 \mu \mathrm{M})$ for 72 h. C. Western blot showing that His-AK2 entered the HaEpi cells. Lane 1, cells incubated without His-AK2; lane 2, PBS buffer from the supernatant after washing the His-AK2incubated cells; lane 3, cells incubated with 5 MM His-AK2 for $48 \mathrm{~h}$ after washed by PBS. D. Immunocytochemistry to show the entered His-AK2 in the cells $48 \mathrm{~h}$ post incubation. The control is the normal cells without treatment.

To confirm that the $A K 2$ knockdown did not induce off-target effects on other genes, the Helicoverpa AK1 (50\% similarity to Helicoverpa AK2) was examined by semi-quantity RT-PCR. Results showed that $A K 2$ knockdown did not affect the mRNA level of $A K 1$ (Figure 4D), indicating that no markedly off-target effects was induced by $A K 2$ RNAi.

\section{AK2 knockdown suppresses haemocyte proliferation}

Circulating haemocytes were calculated after $A K 2$ knockdown by feeding $d s A K 2$-expressing $E$. coli to the newly hitched larvae to examine the role of AK2 in cell proliferation. As expected, AK2 knockdown caused the cell number of circulating haemocytes in the 6th instar $72 \mathrm{~h}$ larvae decrease, compared with the $d s G F P$-expressing E. coli fed control (Figure 5). This finding indicates that AK2 is necessary for the proliferation of circulating haemocytes.

\section{AK2 knockdown decreased the gene transcripts}

The transcripts of some genes involved in development were examined to demonstrate the molecular mechanism of growth retardation and delayed development of larvae after $A K 2$ knockdown by feeding $d s A K 2$-expressing $E$. coli.
The results of semi-quantitative RT-PCR showed that knockdown of $A K 2$ caused suppression of the molting hormone nuclear receptor $E c R B 1$, transcription factors USP1 and $B r$, as well as protein kinase $A K T$ genes (Figure 6). These results suggest that $A K 2$ knockdown decreased the gene transcripts.

\section{Discussion}

The subcelluar localization of AK2 in the mitochondria indicates that it plays a unique role in regulating cell energy homeostasis to balance ATP/ADP between cytosol and mitochondria [6]. H. armigera AK2 localizes in the mitochondria, too. $H$. armigera AK2 shows high identity to other AK2 from various animals, including mammals, indicating that its function in regulating the growth and development of organisms is conserved. The current work demonstrates that AK2 promotes cell growth and proliferation in larval growth and development.

AK2 is necessary for the survival of Drosophila, because the lack of AK2 gene leads to growth defects and death [11]. The constitutive expression pattern of Helicoverpa AK2 implies that AK2 is essential for the development and growth of insect. $A K 2$ knockdown in $H$. armigera results in growth defects, including growth 


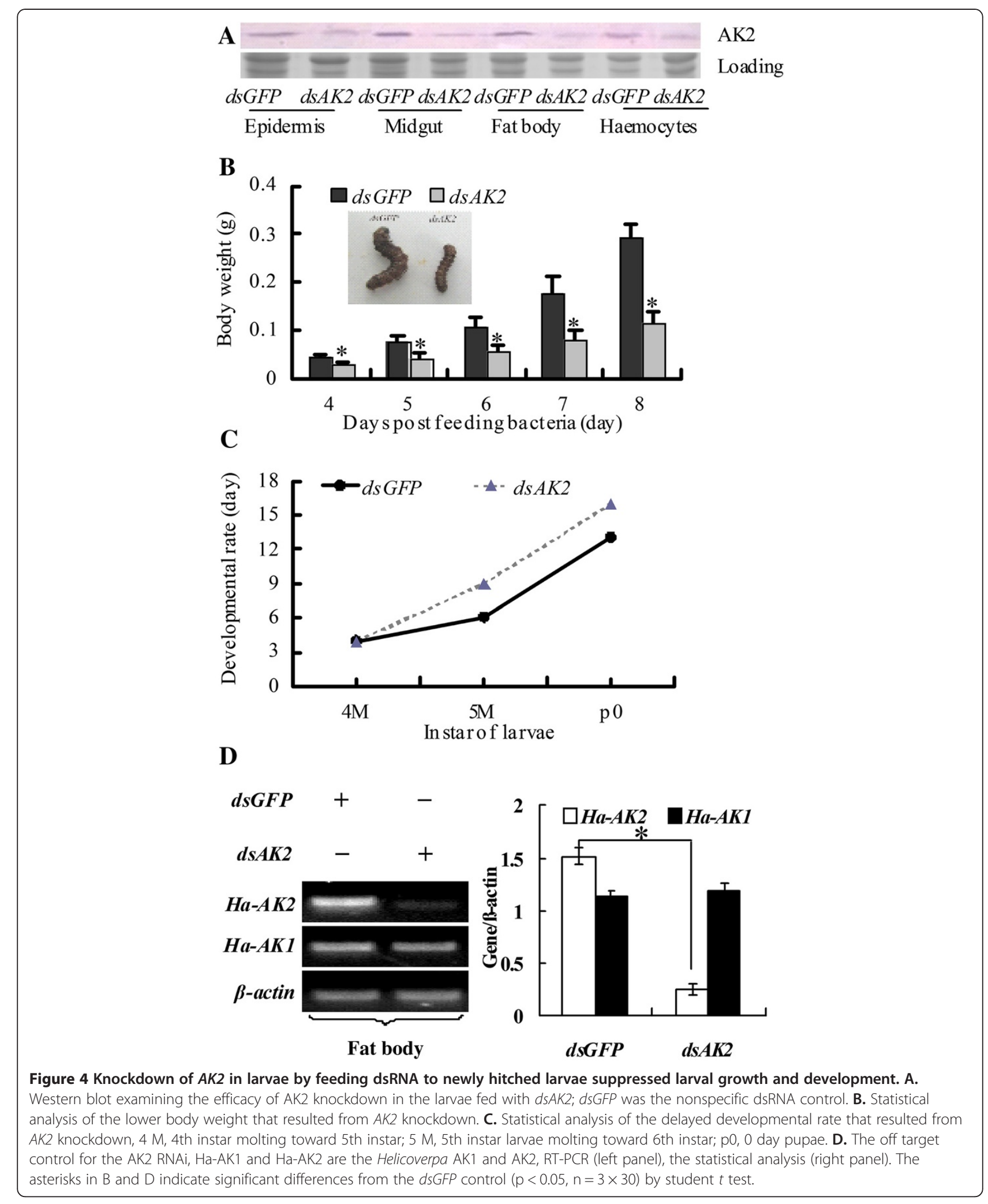

retardation, body weight decrease, and development delay. However, the larvae ultimately experienced pupae and advanced to adult. This might because that RNAi cannot deplete AK2 gene completely as the mutation in Drosophila. Mammalian AK2 is increased expression during adipocyte and B cell differentiation [16]. However, in 


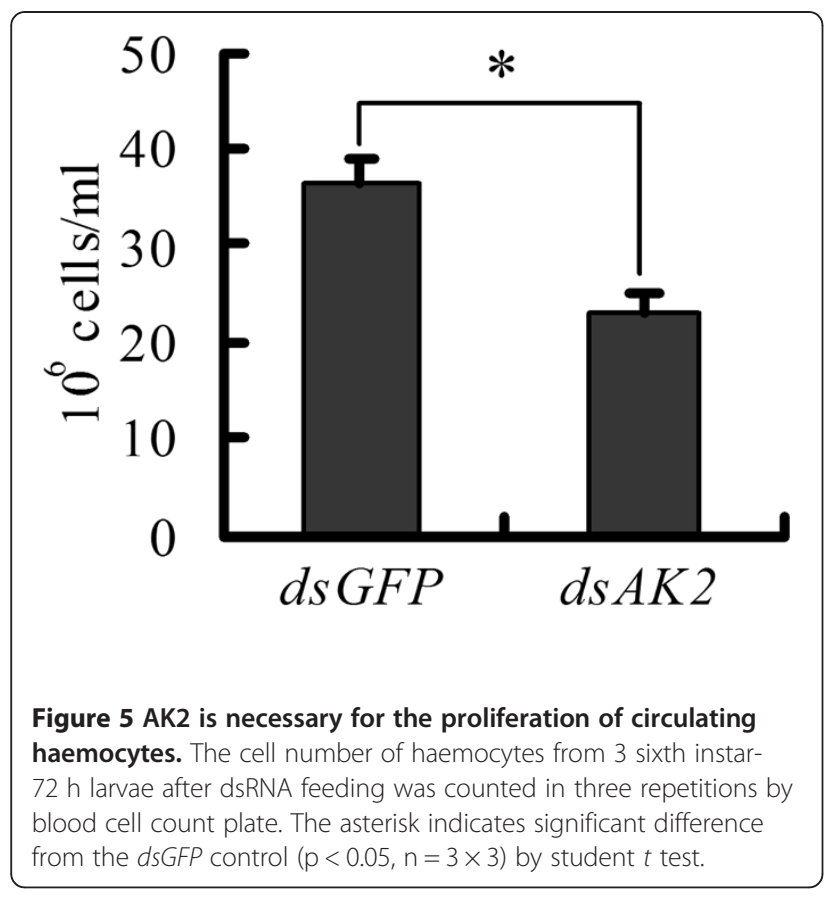

Drosophila, the mRNA and protein of AK2 are detected in the embryo, larva, and adult [17]. Helicoverpa AK2 is expressed in the examined tissues consistently during development. The reason of the different expression profiles in mammals and insects might because the difference between the organisms.

AK2 silencing resulted in development arrest might due to the suppression of the gene expression involved in development. EcRB1, USP1, and Broad are involved in 20E signaling pathway [18]. The protein kinase $A K T$ promotes cell proliferation and inhibits apoptosis [19]. The suppression of these genes after AK2 knockdown might be related to the larval growth arrest and development delay.

Reports state that high ADP concentration causes damage to the cells [20]. AK1 knockout in mice shows no gross abnormalities in nucleotides levels under normal condition; but under hypoxia hypoxia AK1 knockout hearts, intracellular ATP levels was decreased, Pi/ ATP ratio was increased and generation of adenosine was suppressed [21]. ADP levels are accumulated during repetitive contractions of skeletal muscle in AK1 knockout mice [22]. In yeast disruption of AK gene causes accumulation of ATP in the mitochondrial intermembrane space, thus suppress adenine nucleotide translocator exported ATP in exchange for ADP [23].

Human AK2 plays an important role in providing the energy required for the proliferation of haematopoietic precursors [12]. Overexpression of AK promoted ATP production notably in yeasts [24], indicating that overexpressing AK2 supplies adequate ATP for cell proliferation. Our study shows that recombinant expressed AK2 promotes HaEpi cell growth and viability in vitro by MTT assay. MTT assay indicates cell growth and viability; however, it is also often used in cell proliferation detection. For example, the cell survival promoted by overexpressed AK4 under environmental stress [25] and the proliferation of MCF-7 human breast cancer cells in various treatments [26]. The in vivo function of Helicoverpa AK2 to promote cell proliferation is confirmed by the decrease in the number of circulating haemocytes after AK2 knockdown. Insect-circulating haemocytes are supplied by haemopoiesis in the haemopoietic organs or by mitotic division of a circulating stem cell [27]. AK2 knockdown decreases circulating haemocytes, suggesting that AK2 functions in promoting cell proliferation.

The recombinant expressed non-secreted proteins are able to enter the invertebrate heamocytes after being injected into the heamolymph [28], which might because the endocytosis of the invertebrate heamocytes. We found the recombinant expressed non-secreted AK2 is able to enter the cultured epidermal cells. The mechanism of the recombinant expressed protein entering the cultured cells without degradation might because that the endocytosis
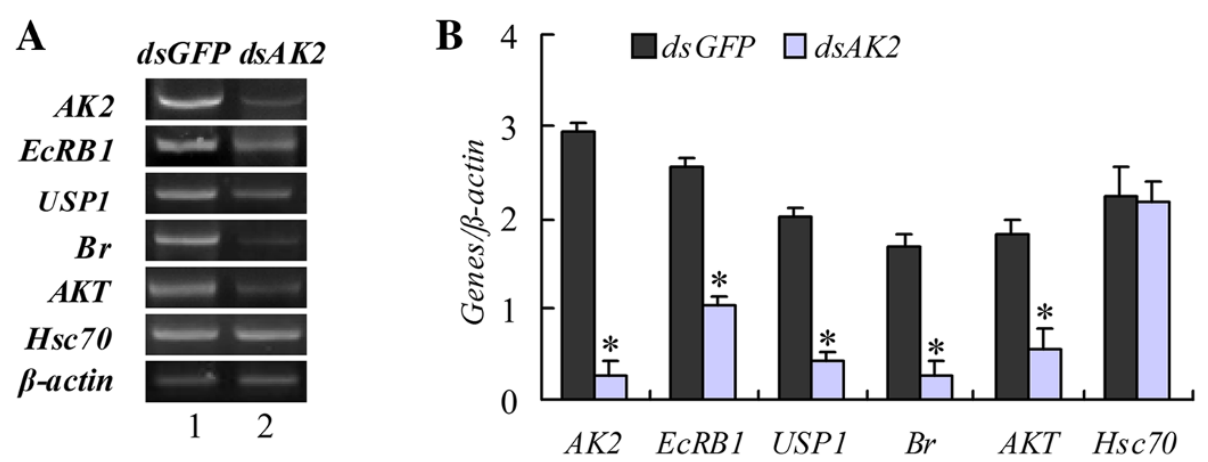

Figure 6 Analysis of gene transcripts in fat body of the fifth instar molting larvae after AK2 knockdown by feeding dsRNA to newly hitched larvae. A. Semi-quantitative RT-PCR, Lane 1, dsGFP-feeding larvae; lane 2, dsAK2-feeding larvae. B. Statistical analysis of results in A. The asterisk indicates significant difference from the control $(p<0.05, n=3)$ by student $t$ test. 
ability of the cells, the culture medium, or the culture temperature is different from the mammals.

\section{Conclusions}

H. armigera AK2 shows high identity to other AK2 from various animals. AK2 is essential to the larval growth and development. The function of AK2 is to promote cell growth. The recombinant expressed AK2 in E. coli is able to promote cell growth and viability in vitro. AK2 is necessary for maintaining the circulating haemocytes number. AK2 is involved in regulating mRNA levels of the genes involved in insect growth and development.

\section{Methods}

\section{Experimental animal}

The cotton bollworm was maintained in the lab on an artificial diet described in a previous work under a daily photoperiod of $14 \mathrm{~h}$ at $27^{\circ} \mathrm{C}$ [29].

\section{Bioinformatics analysis and phylogenetic tree analysis of the AK2 gene}

$A K 2$ was obtained by sequencing the constructed cDNA library. Identity analysis was performed for $A K 2$ through BLASTX (http://www.ncbi.nlm.nih.gov/). The AK domain of the deduced protein was achieved using ExPASy (http://au.expasy.org). The phylogenetic tree for $A K$ was produced using MEGA 3.1 (Molecular Evolutionary Genetics Analysis, Version 3.1).

\section{Recombinant expression of AK2 and antiserum preparation}

The ORF of AK2 (726 bp) was amplified from the cDNA library using the primers AK2ExpF (5'-tactcaggatc catggtgcagaaaggtcct- $\left.3^{\prime}\right)$ and AK2ExpR (5'-tactcactcgagt tagaatcctcgaagaacagc $-3^{\prime}$ ), with the EcoR I and Xho I restriction sites inserted at the beginning and end of ORF, respectively. The PCR products of $A K 2$ were obtained using the following procedures: the first cycle at $94^{\circ} \mathrm{C}$ for $3 \mathrm{~min}$; the next 35 cycles at $94^{\circ} \mathrm{C}$ for $30 \mathrm{~s}$, $55^{\circ} \mathrm{C}$ for $45 \mathrm{~s}, 72^{\circ} \mathrm{C}$ for $30 \mathrm{~s}$; and the final cycle at $72^{\circ} \mathrm{C}$ for $10 \mathrm{~min}$. Subsequently, the products were inserted into the restriction sites of the pET30a plasmid.

The recombinant pET30a- $A K 2$ plasmid was transformed into $E$. coli Rosetta host cells. The target protein was then induced by isopropyl- $\beta$-D-thiogalactopyranoside (IPTG, $0.01 \mathrm{mM}$ ) in kanamycin/Luria-Bertani $(100 \mu \mathrm{g} / \mathrm{ml})$ medium for $6 \mathrm{~h}$ at $28^{\circ} \mathrm{C}$. Afterward, the cells were collected by centrifuging at $4000 \mathrm{~g}$ for $5 \mathrm{~min}$, resuspended in a phosphate-buffered saline (PBS, $140 \mathrm{mM} \mathrm{NaCl}, 2.7 \mathrm{mM} \mathrm{KCl}, 10 \mathrm{mM} \mathrm{Na} 2 \mathrm{HPO}_{4}$, and $1.8 \mathrm{mM} \mathrm{KH}_{2} \mathrm{PO}_{4}$ ) containing $0.2 \%$ Triton $\mathrm{X}-100$, and then sonicated. The soluble recombinant AK2 protein was purified from the supernatant using His-Bind resin $\left(\mathrm{Ni}^{2+}\right.$-resin) (Novagen, Darmstadt, Germany) following manufacturer instructions. SDS-PAGE (12.5\%) was performed to analyze the purified proteins. The purified protein $(100 \mu \mathrm{g})$ was further purified via SDS-PAGE and the target band was homogenized with $1 \mathrm{ml}$ complete Freund's adjuvant (Sigma, St Louis, MO). The mix was injected into a rabbit once a week for three weeks, and post-immune serum was collected. Western blot analysis was performed to examine antiserum specificity.

\section{Western blot}

After SDS-PAGE, the proteins were electrically transferred onto a nitrocellulose membrane. The membrane was treated using the following procedure with shaking at room temperature: blocking with $2 \%$ nonfat dry milk in TBS for $1 \mathrm{~h}$ followed by incubation in antiserum against Ha-AK2 (1:100 in block solution) overnight. Subsequently, the membrane was washed in TBST $(0.1 \%$ Tween-20 in TBS) for $3 \times 10 \mathrm{~min}$, incubated in peroxidase-conjugated goat-anti-rabbit IgG (1:10000 in blocking solution) for $4 \mathrm{~h}$, followed by $3 \times 10 \mathrm{~min}$ washes with TBST and $1 \times 10 \mathrm{~min}$ wash using TBS. The target protein was then visualized by allowing peroxidase to react with a peroxidase-staining reaction mixture $[1 \mathrm{ml} \mathrm{4-}$ chloro-1-naphtholin methanol $(6 \mathrm{mg} / \mathrm{ml}) ; 9 \mathrm{ml}$ TBS; $6 \mu \mathrm{l}$ $\left.\mathrm{H}_{2} \mathrm{O}_{2}\right]$ in the dark for $5 \mathrm{~min}-30 \mathrm{~min}$.

\section{Semiquantitative RT-PCR}

Total RNAs were isolated from the tissues using Unizol reagent. Total RNA $(2 \mu \mathrm{g})$ was used for reverse transcription of the first-strand cDNA using M-MLV Reverse Transcriptase (Sangon, Shanghai, China). The resulting cDNAs were used as templates in PCR reactions. Three independent experiments were performed, and data were analyzed using the Quantity One software (Bio Rad, Hercules, CA, USA).

\section{Immunocytochemistry}

HaEpi cells [15] were seeded on a cover glass in a 24well tissue culture plate and cultured at $27^{\circ} \mathrm{C}$. When the cells grew to a confluence of $80 \%$, the medium was removed from the dish, and the prewarmed $\left(37^{\circ} \mathrm{C}\right)$ medium containing Mitotracker probes was added (50 nM) (Invitrogen, USA). The cells were then incubated at $27^{\circ} \mathrm{C}$. After $30 \mathrm{~min}$, the medium was replaced and cells were washed with PBS. The cells were then fixed in $4 \%$ paraformaldehyde solution for $10 \mathrm{~min}$ at room temperature. After $2 \times 5 \mathrm{~min}$ with PBS, the cells were permeabilized in PBS containing 0.2\% Triton X-100 for $10 \mathrm{~min}$ and blocked with $2 \%$ bovine serum albumin (BSA) for $30 \mathrm{~min}$ at $37^{\circ} \mathrm{C}$. Following blocking, cells were incubated with anti-AK2 (diluted 1:100 in blocking buffer) overnight at $4^{\circ} \mathrm{C}$, and then washed $3 \times 5$ min with PBS and incubated with a secondary antibody (goat anti-rabbitAlexa Fluor 488) diluted to $1: 1000$ at $37^{\circ} \mathrm{C}$ for $1 \mathrm{~h}$. After 
washing with PBS, the cells were stained with 4'-6-Diamidino-2-phenylindole dihydrochloride (DAPI; AnaSpec Inc., San Jose, CA; $1 \mu \mathrm{g} / \mathrm{ml}$ in water) for $10 \mathrm{~min}$ at RT. Fluorescence was detected using an Olympus BX51 fluorescence microscope (Olympus Optical Co., Tokyo, Japan).

\section{MTT cell proliferation assay}

HaEpi cells were seeded in a 96-well tissue culture plate and cultured at $27^{\circ} \mathrm{C}$ until they reached the desired confluence. Indicated concentrations of recombinantly expressed AK2 $(0.078,0.313,1.25,5$, and $20 \mu \mathrm{M})$ were added, as well as VP28, which served as the control. After $72 \mathrm{~h}$, the cells were treated with MTT $(5 \mathrm{mg} / \mathrm{ml}$, $20 \mu \mathrm{l} /$ well) (Sangon, Shanghai, China) for 6 hours. Formazan was dissolved in DMSO $(150 \mu \mathrm{l} /$ well $)$, and absorbance at $490 \mathrm{~nm}$ was determined. The analysis was repeated five times for each concentration.

\section{RNAi in larvae via bacterial feeding}

Full-length AK2 was cloned by PCR using primers AK2expF2 (tactcagcggccgcatggctccagcagctcctgca) and AK2expR2 (tactcactcgagttactgggccgccetttgctt) with the EcoR I and Xho I restriction sites inserted at the beginning and end of AK2. The PCR products were then inserted into the restriction sites of the RNAi vector L4440. The constructed vector was transformed into HT115 (DE3) bacteria. The target dsRNA was induced by isopropyl- $\beta$-D-thiogalactopyranoside (IPTG, $0.5 \mathrm{mM}$ ) in $200 \mathrm{ml}$ Luria-Bertani medium containing ampicillin $(100 \mu \mathrm{g} / \mathrm{ml})$ and tetracycline $(12.5 \mathrm{mg} / \mathrm{ml})$ for $4 \mathrm{~h}$ at $37^{\circ} \mathrm{C}$ to $\mathrm{OD}_{600}=0.6$. The feeding bacteria was collected from $200 \mathrm{ml} \mathrm{LB}$ via centrifugation at $4000 \mathrm{~g}$ for $10 \mathrm{~min}$, after which it was resuspended in $1 \mathrm{ml}$ sterile water for $H$. armigera feeding assay. The artificial diet was cut into $10 \mathrm{~mm} \times 10 \mathrm{~mm} \times 2 \mathrm{~mm}$ pieces, and a $50 \mu$ suspension of the bacteria cells expressing ds $A K 2$ was overlaid onto each diet piece. Bacteria-expressing dsGFP was used as control and was prepared by the same methods. Diet was refreshed daily. Each treatment contained 30 larvae. Three replicates were made for statistical analysis. The processes of insect development, molting, and metamorphosis were tracked daily. Each individual was weighed using an electronic balance (0.0001 g) (Sartorius, Goettingen, Germany) at given developmental stages. Total RNA of body fat from the fifth instar larvae was extracted for RT-PCR analysis. The present phenotype was photographed using a Canon (Powershot A 610) digital camera.

\section{Haemocyte counting}

Hemolymph with haemocytes from the larvae was diluted 50 -fold by PBS with glutathione $(2 \mathrm{mg} / \mathrm{ml})$. The diluted haemocytes were distributed on the blood cell count plate, and the cell number was counted under a microscope (Olympus Optical Co., Tokyo, Japan). Each group contained 3 larvae and the count on each larva was repeated 3 times. The number of haemocytes was statistically calculated.

\section{Additional file}

Additional 1: Figure S1. Bioinformatic and phylogenetic analysis of Helicoverpa AK2. A. CDNA and deduced amino acid sequence of AK2. The shadowed amino acids indicate the ADK domain, in which the boxed amino acids show the ADK_lid domain. B. Multiple alignments of AK2 amino acid sequences with those of corresponding genes obtained from other animals. C. Phynogenetic analysis of AK2 from different organisms by the neighbor-joining method in MEGA. The numbers above the branches indicate bootstrap values shown as percentage, whereas the scale bar displays the number of substitutions per site. The sequences (with GenBank accession numbers) used for the analysis included D. melanogaster (NP_523836), Aedes aegypti (XP_001662844), Danio rerio (NP_997761), Mus musculus (BAE40035), H. sapiens (BAG58139), Anopheles gambiae (XP_318704), Homo sapiens A (NP_001616), H. sapiens B (NP_037543), M. musculus A (NP_001029138), M. musculus B (NP_058591), Tribolium castaneum (XP_972103), Rattus norvegicus (BAA02378), R. norvegicus A (NP_112248), R. norvegicus B (NP_001029139), and Xenopus tropicalis (NP_001004791).

\section{Competing interests}

The authors declare that they have no competing interests.

\section{Authors' contributions}

Ru-Ping Chen performed the experiments on larvae and drafted the manuscript, Chun-Yan Liu did the work on cell line, Hong-Lian Shao maintained HaEpi cells, Wei-Wei Zheng cloned the AK2 CDNA, Jin-Xing Wang and Xiao-Fan Zhao designed and directed the study and write the manuscript. All authors read and approved the final manuscript.

\section{Acknowledgments}

This work was supported by grants from the National Natural Science Foundation of China (No. 30970404), the National Basic Research Program of China (973 Program, 2012CB114101), Shandong Provincial Natural Science Foundation, China (Y2007D51). We are grateful to Dr. Marek Jindra and Masako Asahina of the Biology Center, Czech Academy of Sciences, and the Department of Molecular Biology, University of South Bohemia, Czech Republic, for providing plasmids L4440 and HT115 (DE3).

\section{Author details}

${ }^{1}$ The Key Laboratory of Plant Cell Engineering and Germplasm Innovation, Ministry of Education; Shandong Provincial Key Laboratory of Animal Cells and Developmental Biology, School of Life Sciences, Shandong University, Shandong, Jinan 250100, China. ${ }^{2}$ Hubei Key Laboratory of Insect Resource Application and Sustainable Pest Control and Institute of Urban and Horticultural Pests, College of Plant Science and Technology, Huazhong Agricultural University, Hubei, Wuhan 430070, China.

Received: 3 May 2012 Accepted: 20 September 2012 Published: 28 September 2012

\section{References}

1. Dzeja PP, Terzic A: Phosphotransfer networks and cellular energetics. J Exp Biol 2003, 206(Pt 12):2039-2047.

2. Zeleznikar RJ, Dzeja PP, Goldberg ND: Adenylate kinase-catalyzed phosphoryl transfer couples ATP utilization with its generation by glycolysis in intact muscle. J Biol Chem 1995, 270(13):7311-7319.

3. Glaser M, Nulty W, Vagelos PR: Role of adenylate kinase in the regulation of macromolecular biosynthesis in a putative mutant of Escherichia coli defective in membrane phospholipid biosynthesis. J Bacterio/ 1975, 123(1):128-136. 
4. Konrad M: Molecular analysis of the essential gene for adenylate kinase from the fission yeast Schizosaccharomyces pombe. J Biol Chem 1993, 268 (15):11326-11334.

5. Panayiotou C, Solaroli N, Xu Y, Johansson M, Karlsson A: The characterization of human adenylate kinases 7 and 8 demonstrates differences in kinetic parameters and structural organization among the family of adenylate kinase isoenzymes. Biochem J 2011, 433(3):527-534.

6. Khoo JC, Russell PJ: Isoenzymes of adenylate kinase in human tissue. Biochim Biophys Acta 1972, 268(1):98-101.

7. Gellerich FN: The role of adenylate kinase in dynamic compartmentation of adenine nucleotides in the mitochondrial intermembrane space. FEBS Lett 1992, 297(1-2):55-58.

8. Janssen E, de Groof A, Wijers M, Fransen J, Dzeja PP, Terzic A, Wieringa B: Adenylate kinase 1 deficiency induces molecular and structural adaptations to support muscle energy metabolism. J Biol Chem 2003, 278(15):12937-12945.

9. Zhai R, Meng G, Zhao Y, Liu B, Zhang G, Zheng X: A novel nuclearlocalized protein with special adenylate kinase properties from Caenorhabditis elegans. FEBS Lett 2006, 580(16):3811-3817.

10. Pannicke U, Honig M, Hess I, Friesen C, Holzmann K, Rump EM, Barth TF, Rojewski MT, Schulz A, Boehm T, et al: Reticular dysgenesis (aleukocytosis) is caused by mutations in the gene encoding mitochondrial adenylate kinase 2. Nat Genet 2009, 41(1):101-105.

11. Fujisawa K, Murakami R, Horiguchi T, Noma T: Adenylate kinase isozyme 2 is essential for growth and development of Drosophila melanogaster. Comp Biochem Physiol B Biochem Mol Biol 2009, 153(1):29-38.

12. Lagresle-Peyrou C, Six EM, Picard C, Rieux-Laucat F, Michel V, Ditadi A, Demerens-de Chappedelaine C, Morillon E, Valensi F, Simon-Stoos KL, et al: Human adenylate kinase 2 deficiency causes a profound hematopoietic defect associated with sensorineural deafness. Nat Genet 2009, 41(1):106-111.

13. Kohler C, Gahm A, Noma T, Nakazawa A, Orrenius S, Zhivotovsky B: Release of adenylate kinase 2 from the mitochondrial intermembrane space during apoptosis. FEBS Lett 1999, 447(1):10-12.

14. Lee HJ, Pyo JO, Oh Y, Kim HJ, Hong SH, Jeon YJ, Kim H, Cho DH, Woo HN, Song $S$, et al: AK2 activates a novel apoptotic pathway through formation of a complex with FADD and caspase-10. Nat Cell Biol 2007, 9 (11):1303-1310.

15. Shao HL, Zheng WW, Liu PC, Wang Q, Wang JX, Zhao XF: Establishment of a new cell line from lepidopteran epidermis and hormonal regulation on the genes. PLoS One 2008, 3(9):e3127.

16. Burkart A, Shi X, Chouinard M, Corvera S: Adenylate kinase 2 links mitochondrial energy metabolism to the induction of the unfolded protein response. J Biol Chem 2011, 286(6):4081-4089.

17. Noma T, Murakami R, Yamashiro Y, Fujisawa K, Inouye S, Nakazawa A: cDNA cloning and chromosomal mapping of the gene encoding adenylate kinase 2 from Drosophila melanogaster. Biochim Biophys Acta 2000, 1490(1-2):109-114.

18. Riddiford LM, Hiruma K, Zhou XF, Nelson CA: Insights into the molecular basis of the hormonal control of molting and metamorphosis from Manduca sexta and Drosophila melanogaster. Insect Biochem Molec 2003, 33(12):1327-1338.

19. Zhang $X$, Tang N, Hadden TJ, Rishi AK: Akt, FoxO and regulation of apoptosis. Biochim Biophys Acta 2011, 1813(11):1978-1986.

20. Heine $P$, Braun N, Heilbronn A, Zimmermann H: Functional characterization of rat ecto-ATPase and ecto-ATP diphosphohydrolase after heterologous expression in CHO cells. Eur J Biochem 1999, 262(1):102-107.

21. Pucar D, Janssen E, Dzeja PP, Juranic N, Macura S, Wieringa B, Terzic A: Compromised energetics in the adenylate kinase AK1 gene knockout heart under metabolic stress. J Biol Chem 2000, 275(52):41424-41429.

22. Hancock CR, Brault JJ, Wiseman RW, Terjung RL, Meyer RA: 31P-NMR observation of free ADP during fatiguing, repetitive contractions of murine skeletal muscle lacking AK1. Am J Physiol Cell Physiol 2005, 288(6):C1298-1304.

23. Bandlow W, Strobel G, Zoglowek C, Oechsner U, Magdolen V: Yeast adenylate kinase is active simultaneously in mitochondria and cytoplasm and is required for non-fermentative growth. Eur J Biochem 1988, 178(2):451-457.

24. Sakai $Y$, Rogi T, Yonehara T, Kato N, Tani Y: High-level ATP production by a genetically-engineered Candida yeast. Biotechnology (N Y) 1994, 12(3):291-293.
25. Liu R, Strom AL, Zhai J, Gal J, Bao S, Gong W, Zhu H: Enzymatically inactive adenylate kinase 4 interacts with mitochondrial ADP/ATP translocase. Int J Biochem Cell Biol 2009, 41(6):1371-1380.

26. Duo J, Ying GG, Wang GW, Zhang L: Quercetin inhibits human breast cancer cell proliferation and induces apoptosis via $\mathrm{Bcl}-2$ and $\mathrm{Bax}$ regulation. Mol Med Report 2012, 5(6):1453-1456.

27. Yamashita M, Iwabuchi K: Bombyx mori prohemocyte division and differentiation in individual microcultures. J Insect Physiol 2001, 47(4-5):325-331.

28. Chen AJ, Wang S, Zhao XF, Yu XQ, Wang JX: Enzyme E2 from Chinese white shrimp inhibits replication of white spot syndrome virus and ubiquitinates its RING domain proteins. J Virol 2011, 85(16):8069-8079.

29. Zhao XF, Wang JX, Xu XL, Schmid R, Wieczorek H: Molecular cloning and characterization of the cathepsin B-like proteinase from the cotton boll worm, Helicoverpa armigera. Insect Mol Biol 2002, 11(6):567-575.

doi:10.1186/1471-2199-13-31

Cite this article as: Chen et al:: Adenylate kinase 2 (AK2) promotes cell proliferation in insect development. BMC Molecular Biology 2012 13:31.

\section{Submit your next manuscript to BioMed Central and take full advantage of:}

- Convenient online submission

- Thorough peer review

- No space constraints or color figure charges

- Immediate publication on acceptance

- Inclusion in PubMed, CAS, Scopus and Google Scholar

- Research which is freely available for redistribution

Submit your manuscript at www.biomedcentral.com/submit
C) Biomed Central 